\title{
School Effects, Gender and Socioeconomic Differences in Reading Performance: A Multilevel Analysis
}

\author{
Perparim Shera ${ }^{1}$ \\ ${ }^{1}$ University of Tirana, Albania \\ Correspondence: Perparim Shera, Faculty of Natural Sciences, University of Tirana, Tirana, Albania. E-mail: \\ perparim.shera@fshn.edu.al
}

Received: August 21, 2014

Accepted: September 25, 2014 Online Published: October 28, 2014

doi:10.5539/ies.v7n11p28

URL: http://dx.doi.org/10.5539/ies.v7n11p28

\begin{abstract}
The purpose of this paper is to examine the characteristics of Albanian secondary schools, which are associated with reading achievement and the effects of gender and socio-economic status on reading performance of 15-year-old students. This study used data on the background and achievement of 4,596 students in 181 Albanian schools from the 2009 Programme for International Student Assessment (PISA). Given the nested structure of the data, two-level Hierarchical Linear Modeling (HLM) methods were used to address multilevel research questions. About a third of the total variance in reading performance lies between schools, indicating that school characteristics are important in predicting student achievement. The results clearly reveal the significant relationships of socio-economic status (SES) and gender with student achievement, even after controlling for family structure (two parent families versus others), learning strategies use, and reading engagement. There is also a substantial variability among schools on gender difference in student performance and the effect of SES on student performance. The results from the between-school model suggest that school type, school SES and classroom environment are significant predictors of school performance. Moreover, gender gap in reading performance is associated with school sector (public/private), school location (urban/rural), and average reading engagement; and SES effect on student performance is associated with school type (general/vocational), school location and average reading engagement. The characteristics of schools that make them excellent and more equitable are summarized.
\end{abstract}

Keywords: gender, hierarchical linear modeling, PISA, reading performance, socio-economic status

\section{Introduction}

During the past decade, education reform in Albania has focused on improving student learning outcomes and equality of educational outcomes and opportunities. Raising achievement levels for all students (excellence) while narrowing the gaps between groups (equity), was one of the specific objectives for the Educational Excellence and Equity project started in 2006 (World Bank, 2006). Evidence from the Programme for International Student Assessment (PISA) has revealed low achievement levels of Albanian schools and stark inequalities in educational achievements. Therefore, it is of great interest for researchers to investigate questions and provide insight on the quality and equity of education in Albania. More specifically, identifying factors associated with achievement levels and achievement gaps has been of increasing need among educators and policy makers recently in Albania.

Considerable research has recently accumulated on the effects of school characteristics on academic achievement. Previous research on school effects has produced contradictory results. In one of the most cited works, Coleman et al. (1966) found that school effects on student achievement existed but were less important than student backgrounds. Later, Hanushek (1997) supported Coleman findings claiming that no strong or consistent relationship exists between school inputs and student performance. However, according to Gamoran and Long (2007), a number of sociologists have suggested that Coleman's findings had several problems. By contrast, many other studies have revealed that school characteristics make a significant difference in student achievement (e.g., Fuller \& Clarke, 1994; Greenwald, Hedges \& Laine, 2006; Lee, 2000; Willms \& Somers, 2001). In particular, the importance of school structure variables, such as location and sector (e.g., Lubienski, 2006; Organisation for Economic Co-operation and Development [OECD], 2010a), school composition variables, such as school socioeconomic status (SES) (e.g., Caldas \& Bankston, 1997; Ewijk \& Sleegers, 2010; Ho \& Willms, 
1996; Konstantopoulos, 2006; Lee \& Bryk, 1989), school environment (e.g., Ma \& Klinger, 2000; OECD, 2010b), and school resources (e.g., Rutter \& Maughan, 2002), has been demonstrated in previous research. These variables are also likely to relate to student achievement, because PISA 2009 results indicate that the average achievement in reading varies considerably across schools in Albania (OECD, 2010b). However, school effects on student performance may decrease or disappear once peer and individual effects are considered. For example, S. Lubienski and C. Lubienski (2005) argued that although student performance was greater in private schools, student performance was greater in public schools whether students are in the same socioeconomic class. Consequently, previous research suggests that the effects of the most important school variables vary across studies and countries.

A common finding across numerous studies has been that students' SES and academic achievement are positively related (see Sirin, 2005; White, 1982). Despite a variety of SES constructs and different SES-achievement correlations in literature, it is highly likely that SES is an important predictor of student achievement. In this study, SES refers to a combination of characteristics that describe social, economic, and cultural status of a student's family (OECD, 2010a). PISA 2009 study affirmed that, on average, students with more socio-economically advantaged backgrounds perform better (OECD, 2010a). Moreover, several researchers have attempted to identify features of schools where the relationship between SES and student achievement is stronger or weaker (see Caldas \& Bankston, 1997; C. Howley \& A. Howley, 2004; Lee, 2000; Lee \& Bryk, 1989; Lee, Croninger, \& Smith, 1997; Willms, 2003; Zhao, Valcke, Desoete, \& Verhaeghe, 2012). However, no previous research in Albania has explored school-level characteristics associated with achievement gaps by SES.

Gender achievement gaps have widely been reported in literature. Considerable evidence from previous research suggests that, on average, girls outperform boys in reading achievement. According to PISA 2009, out of 75 participating countries, Albania displays the largest gender achievement gap in reading favoring girls. Therefore, understanding gender differences in academic achievement has become an important educational policy issue in Albania. Recently, researchers have sought to identify not only biological and socio-psychological reasons, but also school characteristics with links to gender gaps in reading achievement (see Arnold, 1992; Grey, Peng, Steward, \& Thomas, 2004; Legewie \& DiPrete, 2012; Machin \& McNally, 2005). Studies thus far have not shown a consistent link between school characteristics and gender achievement gaps. Ma (2008) revealed that school-level variables affecting within-school gender difference in reading vary across countries. In particular, he found that no school-level variables of PISA 2000 were associated with reading gender gap variation in Albania. However, it is still unclear whether there are schools where the achievement gap between girls and boys is higher or lower.

The main objective of this study is to explore achievement, its socioeconomic distribution, and gender gap as functions of school characteristics. This study seeks to provide answers to both excellence (high achievement) and equity (achievement not related to gender and SES) in education. For this purpose, PISA offers a great opportunity to look at how student- and school-level factors affect the quality and equity of educational outcomes (OECD, 2010b). This is accomplished through a school effects study that, as defined by Bidwell and Kasarda (1980), aims "to assess contributions to students' achievements made by school inputs distributed to these students" (p. 425). Following Raudenbush and Willms (1995), for the purpose of this research, a school effect is defined as, "the extent to which attending a particular school modifies a student's outcome" (p. 308). This study employs hierarchical linear modeling (HLM) as a more appropriate method for analyzing data on students nested within schools (see Arnold, 1992; Raudenbush \& Bryk, 2002; Raudenbush \& Willms, 1995; Woltman, Feldstain, MacKay, \& Rocchi, 2012). It addresses four successive research questions as following.

Research Question 1: How much do the strength of SES-reading achievement relationship and the gender gap in reading achievement vary among schools?

Research Question 2: Which school-level characteristics are the most significant predictors of average student reading achievement at the school level?

Research Question 3: What school-level characteristics are associated with a smaller or larger gap in reading performance between boys and girls?

Research Question 4: What school-level characteristics are associated with the effect of SES on reading achievement? 


\section{Method}

\subsection{Sample and Data}

I conducted the present study using Albania datasets provided by PISA 2009. As described in OECD (2012), PISA was an age-based survey assessing 15-year-old students who attend educational institutions in grade 7 or higher. PISA 2009 assessed 4596 students in 181 schools out of 4831 sampled students in 182 sampled schools. The sample represented 34134 students and 1385 schools covering $80 \%$ of the student target population. According to PISA sampling procedures (OECD, 2012), the sample in Albania was designed as a two-stage stratified sample. In the first step, schools were systematically selected using probabilities proportional to their size. In the second step, a maximum of 35 students for selected schools were sampled with equal probability. PISA data contains a series of design weights, specifically student weights and school weights. I used both weights to analyze data and generalize results of this study for the entire population of 15-year-old students and schools they attend in Albania.

\subsection{Measures}

\subsubsection{Dependent Variable}

The outcome variable of this study is student performance in reading. PISA measures student performance on a reading scale that provides an overall assessment of students' acquired reading skills, knowledge and understanding at age 15 (OECD, 2010c). This variable is in the form of five plausible values for the reading achievement of each student. Plausible values are not test scores for individuals, but they are suited to describe the performance of population. "They are random numbers drawn from the distribution of scores that could be reasonably assigned to each individual" (OECD, 2012, p. 142). In this study, these variables are approximately normally distributed with a mean equal to the country mean and a standard deviation equal to 100 . The HLM statistical methodology used in this study includes an option for averaging plausible values. Thus, HLM software estimates its models for each of five plausible values and then averages model estimates across these values.

\subsubsection{Student-Level Variables}

Socio-economic status. Student SES is an index variable in 2009 PISA data set. It is a composite derived from three other indices: highest occupational status of parents, highest educational level of parents (in years of education according to ISCED), and home possessions (OECD, 2012). It is a factor score from a principal component analysis. The reliability of this scale $(0.71)$ is satisfactory. In this analysis, the SES variable was transformed to a z-scored one with a mean 0 and standard deviation 1, which is also normally distributed.

Gender. This is a dummy-coded variable for student's gender ( $1=$ female, $0=$ male). $49.5 \%$ of Albanian students who participated in the survey are females.

Reading engagement. The PISA 2009 student file contains data about three measures: reading enjoyment, reading diversity, and reading enjoyment time (OECD, 2012). I used principal component analysis with varimax rotation to combine these three measures into a single composite. Only one component with an eigenvalue greater than 1 was identified. This index has a reliability of 0.57 and shows how much the student is engaged in reading. It is an indicator of the student's engagement and interest in reading, and motivation to read. Positive values indicate a more engaged reader and negative values indicate a less engaged reader. This variable is z-scored and has an approximately normal distribution.

Learning strategies use. The approaches to learning in PISA 2009 consist of three measures: memorization, elaboration, and control strategies (OECD, 2012). These variables are provided in PISA student data file. Hence, a new construct was derived from a principal component analysis with varimax rotation. Only one component with an eigenvalue greater than 1 was identified. The reliability of this new measure is 0.74 . Positive values of this measure indicate greater use of learning strategies and negative values indicate lower use of learning strategies. This variable is z-scored and has an approximately normal distribution.

Classroom environment. PISA 2009 provides two measures that indicate teacher-student relations and disciplinary climate in the classroom as perceived by students (OECD, 2012). By using principal component analysis with varimax rotation, I created a new measure that provides information on classroom environment. Only one component with an eigenvalue greater than 1 was identified. This index has a reliability of 0.3 , which is rather low. Positive values of this measure indicate a better classroom environment and negative values indicate a poorer classroom environment. This variable is z-scored and has an approximately normal distribution.

Family structure. I recoded an existing variable to create a dummy-coded variable for family structure. Students living with two parents were coded to 1 . Other students have a 0 on this variable. Approximately $84.1 \%$ of 
Albanian students who participated in PISA 2009 live with both parents.

\subsubsection{School-Level Variables}

Only school variables included in the final analytic models are described below. A few other variables not included in constructed hierarchical models were considered, but they are not presented due to their non-significance. The school measures of this study come from two sources: students and schools. I constructed some school variables as aggregates of student variables in each school. After I averaged student variables across students in each school, then I used the z-scores of these aggregates in this analysis. The resulting variables are close to normally distributed. These school variables are average socio-economic status, average reading engagement, average use of reading strategies, and average classroom environment. School characteristics included in the school-level models are school type, school sector, and school location. For the purpose of this analysis, I created the following dummy coded variables: school type ( $1=$ vocational schools, $0=$ general schools); school sector $(1=$ private schools, $0=$ public schools); school location $(1=$ schools located in urban areas, $0=$ schools located in rural areas).

\subsubsection{Handling Missing Data}

School-level variables in this study had no missing values, whereas the percentage of missing values for student-level variables was very low $(<5 \%)$. Consequently, missing data imputation did not bias the results. Missing values were replaced by applying the regression imputation method that uses the mean adjustment with dummy variable adjustment (J. Cohen, P. Cohen, West, \& Aiken, 2002).

\subsection{Analysis}

\subsubsection{Preliminary Analysis}

Initially, I conducted factor analysis in SPSS to create the new measures as described above. Thus, I applied the model of principal component analysis by using the procedure of Varimax orthogonal rotation to obtain only the components for which the eigenvalue is greater than 1 (Tacq, 1997). Then I conducted univariate analysis to explore descriptive statistics of variables included in this study. I also carried out analysis to check two-tail t-test mean differences and bivariate Pearson correlation for relationships between two variables. Descriptive statistics reported in this study were computed by using both student and school weights provided in PISA 2009 datasets. In order to test the mean differences between groups, I utilized the WesVar statistical software that computes estimates and their variance estimates from survey data using replication methods (OECD, 2009).

\subsubsection{Multilevel Analysis}

The research questions posed in this study are of a multilevel nature. Therefore, I used a multilevel analysis strategy to address these questions. Because of the nested structure of the data (students within schools), I utilized the HLM 6 software to create two-level hierarchical linear models. Although the software allows weighting data at both levels, only the normalized school weights were included in this HLM analysis (Raudenbush, Bryk, Cheong, \& Congdon, 2004). In HLM I did not employ a student-level weight because the student weights within each sampled school are equal. As Lee (2000) suggests, three steps of a typical HLM model were followed in this school-effects study. If readers are interested in more details about the statistical theory and methodology of HLM applied in this study, are referred to (Raudenbush \& Bryk, 2002; Hox, 2002).

Fully unconditional model. The first step involves partitioning of the variance in the dependent variable into its within-school and between-school components. This model contains no student and school variables. The proportion of total variance that lies systematically between schools, called the intraclass correlation (ICC), is computed. Hence, ICC is modeled as a function of school characteristics. Lee (2000) suggests that only when the ICC is more than trivial (i.e., greater than $10 \%$ of the total variance in the outcome), the analyst needs to consider multilevel methods. In this step, the reliability estimate of the outcome variable is also reported. Reliability is defined as the proportion of total variance around each parameter that is parameter variance (Arnold, 1992).

Within-school model. In the second step, the variability in the outcome variable within schools is modeled as a function of student characteristics. In this study, student achievement within each school is modeled as a function of five student characteristics: gender, SES, reading engagement, learning strategies use, classroom environment, and family structure. The other non-significant predictors are removed from the model. This model derives an equation for each school. The regression coefficients (betas in HLM results) estimate the effects of student-level variables on achievement. Furthermore, this model allows us to examine whether mean reading achievement varies significantly among schools. Similarly, it also reveals whether the effects of student-level predictors vary significantly across schools. Recommendations on centering, as discussed by Raudenbush and Bryk (2002) are 
applied for variables included in the model. Effect sizes besides un-standardized coefficients, as suggested by Lee et al. (1997) are reported in HLM results. Reliabilities of slopes are checked whether their values are above 0.1. Raudenbush et al. (2004) recommend fixing any coefficient that has reliability below 0.1 .

Between school model. In this model, school characteristics are added to each of the school-level models in order to explain the variation in each of these parameters. The between school equations contain coefficients (gammas in HLM results) that estimate the effects of school-level characteristics on average achievement, gender difference in achievement, or the SES differentiating effect across the schools. The coefficients (gammas) that are non-significant are removed from the final school-level models. For each of the between-school models that predict within-school parameters (intercept, gender slope and SES slope), statistics estimated by HLM (reliability, parameter variances-tau, tests if tau is greater than 0 , proportion of explained variance) are reported in the table of results. Effect sizes are also computed and indicated. Note that school-level continuous variables included in the models are centered around the grand mean, whereas the dummy variables are kept un-centered.

\section{Results}

\subsection{Descriptive Analysis}

Table 1 displays the average of student-level and school-level variables for schools grouped by location, type, and sector.

Table 1. Characteristics of students and schools ${ }^{\mathrm{f}}$

\begin{tabular}{|c|c|c|c|c|c|c|c|c|c|}
\hline \multirow{2}{*}{ Student variables $^{\mathrm{d}}$} & \multirow{2}{*}{\multicolumn{3}{|c|}{$\begin{array}{c}\text { School location } \\
\text { Urban-Rural }\end{array}$}} & \multirow{2}{*}{\multicolumn{2}{|c|}{$\begin{array}{c}\text { School type } \\
\text { General-Vocational }\end{array}$}} & \multicolumn{3}{|c|}{ School administration } & \multirow[t]{2}{*}{ Total } \\
\hline & & & & & & \multicolumn{3}{|c|}{ Public-Private } & \\
\hline Sample size ${ }^{a}$ & 3073 & & 1523 & 4261 & 335 & 4201 & & 395 & 4596 \\
\hline Reading achievement ${ }^{\mathrm{c}}$ & 404 & $* *$ & 349 & 387 & ** 345 & 378 & ** & 442 & 385 \\
\hline Socio-economic status ${ }^{\mathrm{b}}$ & 0.29 & $* *$ & -0.50 & 0.00 & -0.03 & -0.09 & $* *$ & 0.72 & 0.00 \\
\hline Learning strategies use $\mathrm{b}^{\mathrm{b}}$ & 0.01 & & -0.02 & 0.00 & $* \quad-0.08$ & -0.02 & $* *$ & 0.14 & 0.00 \\
\hline Reading engagement ${ }^{\mathrm{b}}$ & 0.04 & + & -0.07 & 0.00 & -0.11 & -0.02 & $* *$ & 0.16 & 0.00 \\
\hline Classroom environment ${ }^{\mathrm{b}}$ & -0.05 & $* *$ & 0.09 & 0.01 & $* *-0.22$ & -0.04 & $*$ & 0.36 & 0.00 \\
\hline Female $\%$ & 48.5 & & 49.1 & 50.1 & 26.7 & 49 & & 46.7 & 48.7 \\
\hline Two-parent family $\%$ & 88.8 & & 89.6 & 89.5 & 81.4 & 89.0 & & 89.1 & 89.0 \\
\hline \multicolumn{10}{|l|}{ School variables ${ }^{\mathrm{e}}$} \\
\hline Sample size ${ }^{a}$ & 103 & & 78 & 169 & 12 & 164 & & 17 & 181 \\
\hline Average socio-economic status ${ }^{\mathrm{b}}$ & 0.88 & $* *$ & -0.58 & -0.01 & 0.40 & -0.24 & $* *$ & 1.47 & 0.00 \\
\hline Average classroom environment ${ }^{b}$ & -0.17 & + & 0.11 & 0.02 & -0.48 & -0.08 & $* *$ & 0.52 & 0.00 \\
\hline Average reading engagement ${ }^{b}$ & 0.19 & $*$ & -0.13 & 0.00 & -0.08 & -0.08 & $* *$ & 0.51 & 0.00 \\
\hline Average learning strategies ${ }^{\mathrm{b}}$ & 0.07 & & -0.04 & 0.00 & -0.07 & -0.06 & $*$ & 0.38 & 0.00 \\
\hline
\end{tabular}

${ }^{+} \mathrm{p}<0.1 ;{ }^{*} \mathrm{p}<0.05 ; * * \mathrm{p}<0.01$.

${ }^{a}$ Sample sizes are computed unweighted.

${ }^{\mathrm{b}}$ Continuous variable as a $\mathrm{z}$-score $(\mathrm{M}=0, \mathrm{SD}=1)$.

${ }^{\mathrm{c}}$ Reading achievement is represented by five plausible values.

${ }^{\mathrm{d}}$ Group means are computed using student weight with Wesvar software.

${ }^{\mathrm{e}}$ Group means are computed using school weight with one-way ANOVA.

${ }^{\mathrm{f}}$ Three contrasts are tested (urban versus rural, general versus vocational and public versus private).

Group mean differences in reading achievement indicate that there are significant differences between students in urban schools and those in rural schools; between students attending general schools and those attending 
vocational schools; and between students of private schools and those of public schools. These figures suggest that there is a high disparity in achievement across schools, which needs to be explained. Both student SES and school average SES are statistically different between groups by school location and school sector, but they are not statistically different between groups by school type. Moreover, students that attend urban schools are statistically more engaged in reading than students in rural schools; and students in private schools are statistically more engaged in reading than students in public schools. Surprisingly, students in rural schools report, on average, a better classroom environment than students in urban schools. The index of classroom environment is significantly higher for general schools versus vocational schools, and for private schools versus public schools. With regards to the index of learning strategies, there is no significant difference between students in urban and rural schools. However, there is a significant difference between group means by school type and school sector in favor of general schools and private ones respectively. In general, there is a similar pattern in the group mean differences at both levels for all variables. I emphasize here that due to the small number of vocational schools, there is no significant difference between group means for variables at school level. Correlation analysis indicated that there is no evidence of strong relationships between student-level variables. Furthermore, I found that there is a large difference between girls and boys in favor of girls not only in reading achievement but also in reading engagement and learning strategies use.

\subsection{Multilevel Analysis}

Fully unconditional model. Table 2 contains information that corresponds to the first step of HLM analysis. I highlight here two statistics that are important for the next steps. First, the reliability of the outcome variable, estimated at 0.92 with HLM, is high. Second, the computed ICC of 0.3 means that about a third of the total variance in reading achievement occurs between schools. Although it is lower than the average of OECD countries' ICC values estimated at 0.39 (OECD, 2010b), it is relatively high. The relatively high ICC, associated with high reliability, suggests that research for school effects is effectual and fruitful (Lee et al., 1997).

Table 2. HLM fully unconditional model ( $\mathrm{n}=4596$ students in 181 schools $)^{\mathrm{a}}$

\begin{tabular}{|c|c|}
\hline & $\begin{array}{l}\text { Outcome variable: } 15 \text {-year-old } \\
\text { students' performance in reading }\end{array}$ \\
\hline Average achievement & 368.88 \\
\hline Within-school variance (sigma-squared) ${ }^{\mathrm{c}}$ & 6979.72 \\
\hline Between-school variance (tau) & 2969.28 \\
\hline Between-school standard deviation ${ }^{\mathrm{d}}$ & 54.49 \\
\hline HLM reliability (Lambda) & 0.92 \\
\hline Intraclass correlation (ICC) ${ }^{\mathrm{e}}$ & 0.30 \\
\hline Adjusted intraclass correlation ${ }^{\mathrm{f}}$ & 0.32 \\
\hline
\end{tabular}

\footnotetext{
${ }^{a}$ Unweighted sample sizes.

${ }^{\mathrm{b}}$ Student performance is represented by five plausible values.

${ }^{\mathrm{c}}$ This is a variance pooled across schools.

${ }^{\mathrm{d}}$ This is square root of tau.

${ }^{\mathrm{e}}$ ICC represents the proportion of total variance in student performance that is systematically found between schools. It is computed by formula: $\mathrm{ICC}=\mathrm{Tau} /(\mathrm{Tau}+\mathrm{Sigma}$ squared).

${ }^{\mathrm{f}}$ It is computed by formula: $\mathrm{ICC}=\mathrm{Tau} /(\mathrm{Tau}+\mathrm{Lambda} *$ Sigma squared $)$.
}

Within-school model. The results of this model in Table 3 are related to the first research question and are obtained according to the second step of multilevel analysis procedure described above. In this model, I included three demographic variables (SES, gender, and family structure) and two individual behavior variables (reading engagement and learning strategies). Beta coefficients indicate that these five student variables are significant predictors $(\mathrm{p}<0.001)$ of student achievement. Because SES and gender are the variables of interest, the other three variables are used as statistical controls. Hence, reading engagement, learning strategies and family structure are fixed and grand-mean centered, whereas gender and SES are left free and school-mean centered. 
Chi-squared values in the table of random effects indicate that school average reading achievement (intercept) and the effects of SES and gender on student achievement within schools (slopes) vary significantly between schools $(\mathrm{p}<0.001)$. I note also that the reliability values of these parameters are acceptable. The SES effect is moderate, whereas the gender gap in reading performance between boys and girls within schools is large, even after controlling for other variables. Students from low-SES families perform lower than students from high-SES families and girls perform much better than boys, while the other student characteristics are held constant. Finally, results suggest that about $22.2 \%$ of the total pooled within-school variability in the outcome is explained by this model (Sigma-squared is 5428.9), compared to the fully unconditional model.

Table 3. HLM within-school model on 15-year-old students' performance in reading ( $\mathrm{n}=4596$ students in 181 schools) ${ }^{\mathrm{a}}$

\begin{tabular}{llll}
\hline Fixed effects & Beta coefficient & Effect size $^{\mathrm{c}}$ & \\
\hline Student-level independent variables & & & \\
\hline \multicolumn{1}{c}{ Intercept } & $370.95^{* * *}$ & & \\
$\quad$ Socio-economic status & $11.01^{* * *}$ & 0.202 & \\
$\quad$ Gender (female) & $41.02^{* * *}$ & 0.753 & \\
$\quad$ Learning strategies use & $12.89^{* * *}$ & 0.237 & \\
$\quad$ Reading engagement & $8.85^{* * *}$ & 0.162 & $2365.77^{* * *}$ \\
$\quad$ Family structure (two-parent family) & $34.02^{* * *}$ & 0.624 & $285.83^{* * *}$ \\
\hline Random effects & Variance (Tau) & Degrees of freedom & Chi-squared $^{\text {d }}$ \\
\hline Average achievement & 2621.32 & & 174 \\
SES/Achievement slope & 94.85 & & 174 \\
Gender difference & 371.25 & & 174 \\
Reliability & Estimate & & \\
Average achievement & 0.933 & & \\
SES/Achievement slope & 0.272 & & \\
Gender difference & 0.355 & & \\
\hline
\end{tabular}

$* * * \mathrm{p}<0.001$.

${ }^{a}$ Sample sizes are reported unweighted. Parameters on this table are estimated with a two-level HLM using normalized school weights.

${ }^{\mathrm{b}}$ Gender and socio-economic status are group-mean-centered variables. Learning strategies, reading engagement, family structure are grand-mean-centered variables.

${ }^{c}$ Effect sizes are manually computed by dividing the corresponding beta coefficient with the between-school standard deviation of the dependent variable estimated in the fully unconditional model.

${ }^{\mathrm{d}}$ These statistics are based on only 174 of 181 schools that have sufficient data for computation.

Between-school model. The results of this model are displayed in Table 4. The information in this table is relevant to the research questions 2, 3 and 4 . As described in step three of multilevel analysis procedure, average achievement, gender slope, and SES slope are simultaneously modeled as functions of school characteristics. Consequently, three models at school-level are obtained, which explain respectively $43.3 \%, 7.3 \%$, and $8.2 \%$ of the total variance. The percentage of total variance explained is "parameter variance explained" times the reliability (Arnold, 1992). Only significant effects are presented in the constructed models. The results are reported as beta coefficients and in effects size units. Comparing the results of within-school models between the two tables reveals that there is a very little change in the magnitude of effects of student variables used as statistical controls. Moreover, the reliability estimates of random effects have not significantly changed. 
Table 4. HLM between-school model on 15-year-old students' performance in reading ( $\mathrm{n}=4596$ students in 181 schools) ${ }^{\mathrm{a}}$

Fixed effects

A. Outcomes

Average achievement

$379.03 * * *$

Average SES/achievement slope

6.6

Average gender difference

$-2.76^{+}$

\begin{tabular}{|c|c|c|c|c|c|c|}
\hline & \multicolumn{4}{|c|}{ 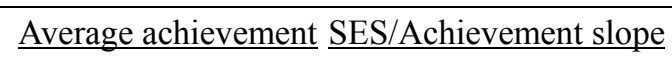 } & \multicolumn{2}{|c|}{ Gender difference } \\
\hline & $\underline{\text { Gamma }}$ & Effect size $^{\mathrm{b}}$ & $\underline{\text { Gamma }}$ & $\underline{\text { Effect size }^{\mathrm{b}}}$ & $\underline{\text { Gamma }}$ & $\underline{\text { Effect size }^{b}}$ \\
\hline \multicolumn{7}{|l|}{ B. Within-School Model (betas) ${ }^{c}$} \\
\hline Socio-economic status & 6.6 & 0.129 & & & & \\
\hline Gender (female) & $-2.76^{+}$ & -0.054 & & & & \\
\hline Learning strategies use & $12.61 * * *$ & 0.246 & & & & \\
\hline Reading engagement & $8.17 * * *$ & 0.160 & & & & \\
\hline Family structure (two-parent family) & $32.97 * * *$ & 0.644 & & & & \\
\hline \multicolumn{7}{|l|}{ C. Between-School Model (gammas) ${ }^{\mathrm{d}}$} \\
\hline Average socio-economic status & $36.36 * * *$ & 0.710 & & & & \\
\hline Average classroom environment & $7.63^{+}$ & 0.149 & & & & \\
\hline Average reading engagement & & & $7.91+$ & 0.812 & $8.65^{+}$ & 0.449 \\
\hline School location (urban/rural) & & & $11.28 *$ & 1.158 & $15.83^{+}$ & 0.822 \\
\hline School type (vocational/general) & $-29.05^{+}$ & 0.567 & $-20.68 *$ & -2.123 & & \\
\hline School sector (public/private) & & & & & $42.07 * * *$ & 2.183 \\
\hline \multicolumn{7}{|l|}{ Random effects } \\
\hline Between school variance (Tau) & 1330.66 & & 43.21 & & 280.37 & \\
\hline Degrees of freedom & 171 & & 171 & & 171 & \\
\hline Chi-squared $^{\mathrm{e}}$ & 1268.48 & & 261.40 & & 274.83 & \\
\hline Variance percentage explained by model ${ }^{\mathrm{f}}$ & $49.2 \%$ & & $54.4 \%$ & & $24.5 \%$ & \\
\hline Reliability estimates $^{\mathrm{e}}$ & 0.881 & & 0.150 & & 0.297 & \\
\hline
\end{tabular}

${ }^{+} \mathrm{p}<0.1 ;{ }^{*} \mathrm{p}<0.05 ; * * \mathrm{p}<0.01 ; * * * \mathrm{p}<0.001$.

${ }^{\text {a }}$ Sample sizes are reported unweighted. Parameters on this table are estimated with a two-level HLM using normalized school weights.

${ }^{\mathrm{b}}$ Effect sizes are computed by dividing HLM gamma coefficients of this model with the between-school standard deviation of the outcome estimated in the within-school model. For average achievement, $\mathrm{SD}=51.2$; for the $\mathrm{SES} /$ achievement slope, $\mathrm{SD}=9.74$; for gender difference, $\mathrm{SD}=19.27$.

${ }^{\mathrm{c}}$ Gender and socio-economic status are group-mean-centered variables. Learning strategies, reading engagement, family structure are grand-mean-centered variables.

d Average socio-economic status, average classroom environment and average reading engagement are country-mean-centered variables.

${ }^{\mathrm{e}}$ These statistics are based on only 171 of 181 schools that have sufficient data for computation.

${ }^{\mathrm{f}}$ Percentage of variance explained in reading achievement is computed by comparing the tau in this model to the tau in the previous model that is unconditional between schools. Similarly, the percentages of variances explained in the SES/achievement and gender slopes are computed by comparing the taus of this model to the corresponding slopes taus in the within-school model that does not contain any school variable. 
School average achievement. I found that two school measures are positively related to reading performance: average socio-economic status (school SES) and average classroom environment. The large effect size of school SES suggests that students attending advantaged schools tend to score much higher than students attending disadvantaged schools. Similarly, students from schools with positive classroom environment achieve higher than students from schools with negative classroom environment, even though the effect size is small. Furthermore, reading achievement is significantly higher in general schools than in vocational schools. This model explains about half of the between-school variance in reading performance.

SES differentiating effect. The results indicate that this equity parameter is explained by average reading engagement, school location, and school type. On average, 54\% of the effect of socioeconomic background on achievement is accounted for by these factors. Schools with more engaged readers tend to have a higher SES effect on reading performance and making them less equitable. Moreover, the figures of Table 4 infer that school location and school type influence the equitable distribution of achievement by SES among students in a school. Specifically, urban schools and general schools are less equitable.

Gender difference. On average, gender gap between girls and boys in reading performance is higher in schools with more engaged readers. The results suggest that even after controlling for average reading engagement, gender difference in achievement is much higher in urban schools than rural ones. Similarly, on average, the difference between girls and boys in achievement is considerably higher in private schools compared to public schools. The variation in gender achievement gaps across schools is modeled by school location, school sector, and average reading engagement. However, the explained variance in gender/achievement slope is relatively low $(25 \%)$.

\section{Discussion}

There is broad agreement that good schools are those that have simultaneously high average achievement and an equitable distribution of achievement among students of different backgrounds. Identifying the characteristics associated with good schools in Albania was the main purpose of this research. This study focused in academic outcomes in terms of effectiveness (i.e., average achievement in reading) and equity (i.e., SES differentiating effect and gender difference). It contributes to our understanding of various features and factors that characterize a good school in Albania. To my knowledge, it is the first study that demonstrates the relationship of school characteristics with students' achievement in reading and achievement distribution by SES and gender, adjusted for several individual characteristics. The study also provides a theoretical framework that identifies significant relationships between newly developed constructs and achievement.

Initially, I explored sources of within-school inequality in reading achievement by considering student SES, gender, reading engagement, learning strategies use, and family structure. According to PISA 2009 results, two student measures, SES and gender, are significantly related to reading achievement. Specifically, there is a medium positive relationship (0.33) between student SES and PISA reading achievement (OECD, 2010a); and there is a large gap between girls and boys (62 points) in PISA reading achievement (OECD, 2010c). In this paper, I further found that these significant relationships still remain even after accounting for other student variables included in this study (reading engagement, learning strategies use, family structure). Moreover, the HLM analysis revealed that the effects of both SES and gender on reading achievement vary significantly among schools.

Another feature of my analysis was to find combinations of school characteristics that produce higher average achievement in reading. The results of modeling the effectiveness parameter revealed the characteristics of schools that relate to school performance. In sum, two indirect measures (average SES and classroom environment) and a demographic feature (school type) predict student achievement. They explain a substantial proportion of the between-school variation in achievement. More specifically, three conclusions are drawn from these results. First, schools with higher mean SES get higher average performance in reading. Consequently, we might conclude that being in a school with high SES students increases the chance for a student to get better results. Second, schools with higher classroom environment indices have, on average, higher achievement in reading. This implies that a student attending a school with a better classroom environment tends to achieve higher in reading. I believe that this conclusion provides a good indicator for policy makers. Taking measures to create a better classroom environment might increase students' learning outcomes. Third, general schools in Albania seem to have significantly higher achievement than vocational schools, even after controlling for school SES and classroom environment. This indicates that typically high-achieving students in Albania choose to attend general schools. However, this is not a surprise in Albania because it is known that students who do not like to go to the university usually attend vocational schools. It is important to note here that when controlling 
for other variables, school sector and school location are no longer significant predictors of school performance. The finding that the effect of school sector vanishes after controlling for other school variables is congruent with results from previous research (e.g., Lee, Franco, \& Albernaz, 2004).

Gender gaps and SES differences in student achievement are two important issues of educational equity. Through HLM analysis, this paper investigated the importance of several school characteristics on the effects of gender and SES on achievement. The predictors of SES effect are school reading engagement, school type, and school location. The predictors of gender effect are school reading engagement, school location, and school sector. Average reading engagement in a school seems to influence both effects. The analysis indicated that the SES/performance relationship is positively stronger in schools with higher mean reading engagement. Similarly, the gender gap in reading achievement is larger for schools with higher mean reading engagement. In terms of policy usefulness, this is not desirable because schools with more engaged students in reading are less equitable. It is not surprising because if a school has more engaged students in reading, it is likely the school has more high-achieving students. Consequently, a question that arises for policy makers from these conclusions is what can be done to make low-achieving students being more engaged in reading. With respect to school location, this study concludes that SES has less of a differentiating effect in rural schools. That is, rural schools are more equitable in distribution of achievement by SES. In addition, gender difference in reading achievement is much higher in urban schools than rural ones. School type is one of the school characteristics found to be related to SES effect but not gender effect on student achievement. Thus, achievement by SES is distributed more equitably in vocational schools than general schools. Moreover, there is strong evidence that school sector is related to gender difference in achievement but not SES effect. This study suggests that gender difference in achievement is considerably higher in public schools than private schools. It might be very useful for policy-makers to recognize the practices of private schools that make them not only more effective but also more equitable.

In summary, it seems that the Albanian educational system is neither effective nor equitable in terms of student achievement in reading. The findings of this study shed light into how the student achievement can be improved by changing student and school factors that are modifiable. For instance, in reality, we might not control and change the SES to improve achievement, but we can change the factors that influence the effect of SES on reading performance. As Montt (2010) writes, "by reducing the strength of the relationship between socioeconomic status and achievement in a school system, the overall distribution of achievement is also equalized" (p. 62). Moreover, Willms (2006) recommends that a mix of interventions will be optimal to achieve both excellence and equity because a combination of factors can jointly maximize these parameters.

However, the results should be cautiously interpreted due to some limitations of this study. First, because this study is correlational, the findings cannot be interpreted as causal claims. Second, PISA is a cross sectional study and does not measure students' prior achievement. Therefore, the strength of impact that school characteristics can have on student learning (achievement gains) cannot be observed. Third, the findings are valid only for 15 -year old students and cannot be generalized for all students. Fourth, PISA does not collect information about teachers, and some school variables are not directly measured. This signals that this study cannot shed light on other school characteristics that might potentially be associated with student achievement. Consequently, there is a need for more comprehensive surveys to investigate whether pre-university schools in Albania play a significant role in raising students' achievement and closing achievement gaps among various groups of students.

\section{References}

Arnold, C. L. (1992). An introduction to hierarchical linear models. Measurement and Evaluation in Counseling and Development, 25(2), 58-90.

Bidwell, C., \& Kasarda, J. (1980). Conceptualizing and measuring the effects of school and schooling. American Journal of Education, 88, 401-430. http://dx.doi.org/10.1086/443540

Caldas, S. J., \& Bankston, C. (1997). The effect of school population socioeconomic status on individual student academic achievement. The Journal of Educational Research, 90(5), 269-277. http://dx.doi.org/10.1080 /00220671.1997.10544583

Cohen, J., Cohen, P., West, S. G., \& Aiken, L. S. (2013). Applied multiple regression/correlation analysis for the behavioral sciences. Routledge.

Coleman, J. S., Campbell, E. Q., Hobson, C. J., McPartland, J., Mood, A. M., Weinfeld, F. D., \& York, R. (1966). Equality of educational opportunity. Washington, DC: U.S. Government Printing Office.

Fuller, B., \& Clarke, P. (1994). Raising school effects while ignoring culture? Local conditions, and the influence 
of classroom tools, rules, and pedagogy. Review of Educational Research, 64(1), 119-157. http://dx.doi.org/10.3102/00346543064001119

Gamoran, A., \& Long, D. A. (2007). Equality of educational opportunity: A 40-year retrospective. In R. Teese, S. Lamb, \& M. Duru-Bellat (Eds.), International studies in educational inequality: Theory and policy. New York: Springer Press.

Gray, J., Peng, W., Steward, S., \& Thomas, S. (2004). Towards a typology of gender related school effects: Some new perspectives on a familiar problem. Oxford Review of Education, 30(4), 529-550. http://dx.doi.org/10.1080/0305498042000303991

Greenwald, R., Hedges, L. V., \& Laine, R. D. (1996). The effect of school resources on student achievement. Review of Educational Research, 66(3), 361-396. http://dx.doi.org/10.3102/00346543066003361

Hanushek, E. A. (1997). Assessing the effects of school resources on student performance: An update. Educational Evaluation and Policy Analysis, 19, 141-164. http://dx.doi.org/10.2307/1164207

Ho, S., \& Willms, J. D. (1996). Effects of parental involvement on eighth-grade achievement. Sociology of Education, 69, 126-141. http://dx.doi.org/10.2307/2112802

Howley, C. B., \& Howley, A. A. (2004). School size and the influence of socioeconomic status on student achievement: Confronting the threat of size bias in national data sets. Education Policy Analysis Archives, 12(52), 1-35. http://dx.doi.org/10.14507/epaa.v12n52.2004

Hox, J. J. (2002). Multilevel analysis: Techniques and applications. New Jersey: Lawrence Erlbaum Associates.

Konstantopoulos, S. (2006). Trends of school effects on student achievement: Evidence from NLS: 72, HSB: 82, and NELS: 92. Teachers College Record, 108(12), 2550-2581. http://dx.doi.org/10.1111/j.1467-9620.2006.00796.x

Lee, V. E. (2000). Using hierarchical linear modeling to study social contexts: The case of school effects. Educational Psychologist, 32, 125-141. http://dx.doi.org/10.1207/S15326985EP3502_6

Lee, V. E., \& Bryk, A. S. (1989). A multilevel model of the social distribution of high school achievement. Sociology of Education, 62, 172-192. http://dx.doi.org/10.2307/2112866

Lee, V. E., Croninger, R. G., \& Smith, J. B. (1997). Course-taking, equity, and mathematics learning: Testing the constrained curriculum hypothesis in U.S. secondary schools. Educational Evaluation and Policy Analysis, 19(2), 99-121. http://dx.doi.org/10.3102/01623737019002099

Lee, V. E., Franco, C., \& Albernaz, A. (2004, April). Quality and equality in brazilian secondary schools: A multilevel cross-national school effects study. Paper presented at the 2004 Annual Meeting of the American Educational Research Association, San Diego, CA.

Legewie, J., \& DiPrete, T. A. (2012). School context and the gender gap in educational achievement. American Sociological Review, 77(3), 463-485. http://dx.doi.org/10.1177/0003122412440802

Lubienski, S. T. (2006). Examining instruction, achievement, and equity with NAEP mathematics data. Education Policy Analysis Archives, 14(14), 1-33.

Lubienski, S. T., \& Lubienski, C. (2005). A new look at public and private schools: Student background and mathematics achievement. Phi Delta Kappan, 86(9), 696-699.

Ma, X. (2008). Within-School Gender Gaps in Reading, Mathematics, and Science Literacy. Comparative Education Review, 52(3), 437-460. http://dx.doi.org/10.1086/588762

Ma, X., \& Klinger, D. A. (2000). Hierarchical linear modelling of student and school effects on academic achievement. Canadian Journal of Education, 25(1), 41-55. http://dx.doi.org/10.2307/1585867

Machin, S., \& McNally, S. (2005). Gender and student achievement in English schools. Oxford Review of Economic Policy, 21, 357-72. http://dx.doi.org/10.1093/oxrep/gri021

Montt, G. (2010). Cross-national differences in educational achievement inequality. Sociology of Education, 84(1), 49-68. http://dx.doi.org/10.1177/0038040710392717

OECD. (2009). PISA Data Analysis Manual: SPSS, Second Edition. OECD Publishing. http://dx.doi.org/10.1787/9789264056275-en

OECD. (2010a). PISA 2009 Results: Overcoming Social Background-Equity in Learning Opportunities and Outcomes (Volume II). OECD Publishing. http://dx.doi.org/10.1787/9789264091504-en 
OECD. (2010b). PISA 2009 Results: What Makes a School Successful?-Resources, Policies and Practices (Volume IV). OECD Publishing. http://dx.doi.org/10.1787/9789264091559-en

OECD. (2010c). PISA 2009 Results: What Students Know and Can Do-Student Performance in Reading, Mathematics and Science (Volume 1). OECD Publishing. http://dx.doi.org/10.1787/9789264091450-en

OECD. (2012). PISA 2009 Technical Report. OECD Publishing. http://dx.doi.org/10.1787/9789264167872-en

Raudenbush, S. W., \& Bryk, A. S. (1986). A hierarchical model for studying school effects. Sociology of education, 59, 1-17. http://dx.doi.org/10.2307/2112482

Raudenbush, S. W., \& Bryk, A. S. (2002). Hierarchical linear models: Applications and data analysis methods (2nd ed.). Thousand Oaks, CA: Sage.

Raudenbush, S. W., \& Willms, J. D. (1995). The estimation of school effects. Journal of Educational and Behavioral Statistics, 20(4), 307-335. http://dx.doi.org/10.2307/1165304

Raudenbush, S. W., Bryk, A. S., Cheong, Y. F., \& Congdon, R. T. (2004). HLM 6: Hierarchical linear and nonlinear modeling. Scientific Software International.

Rutter, M., \& Maughan, B. (2002). School effectiveness findings 1979-2002. Journal of School Psychology, 40(6), 451-475. http://dx.doi.org/10.1016/S0022-4405(02)00124-3

Sirin, S. R. (2005). Socioeconomic status and academic achievement: A meta-analytic review of research. Review of Educational Research, 75(3), 417-453. http://dx.doi.org/10.3102/00346543075003417

Tacq, J. (1997). Multivariate analysis techniques in social science research: From problem to analysis. Sage Publications.

Van Ewijk, R., \& Sleegers, P. (2010). The effect of peer socioeconomic status on student achievement: A meta-analysis. Educational Research Review, 5(2), 134-150. http://dx.doi.org/10.1016/j.edurev.2010.02.001

White, K. R. (1982). The relation between socioeconomic status and academic achievement. Psychological Bulletin, 91, 461-481. http://dx.doi.org/10.1037/0033-2909.91.3.461

Willms, J. D. (2003). Literacy proficiency of youth: Evidence of converging socioeconomic gradients. International Journal of Educational Research, 39(3), 247-252. http://dx.doi.org/10.1016/j.ijer.2004.04.005

Willms, J. D. (2006). Learning divides: Ten policy questions about the performance and equity of schools and schooling systems. Montreal, QC: UNESCO Institute for Statistics. Retrieved from http://unesdoc.unesco.org/images/0014/001470/147066e.pdf

Willms, J. D., \& Somers, M. A. (2001). Family, classroom, and school effects on children's educational outcomes in Latin America. School Effectiveness and School Improvement, 12(4), 409-445. http://dx.doi.org/10.1076/sesi.12.4.409.3445

Woltman, H., Feldstain, A., MacKay, J. C., \& Rocchi, M. (2012). An introduction to hierarchical linear modeling. Tutorials in Quantitative Methods for Psychology, 8(1), 52-69.

World Bank. (2006). Albania-Education Excellence and Equity Program Project. Washington, DC: World Bank. Retrieved from http://documents.worldbank.org/curated/en/2006/04/9422065/albania-education-excellence -equity-program-project

Zhao, N., Valcke, M., Desoete, A., \& Verhaeghe, J. (2012). The quadratic relationship between socioeconomic status and learning performance in China by multilevel analysis: Implications for policies to foster education equity. International Journal of Educational Development, 32(3), 412-422. http://dx.doi.org/10.1016/j.ijedudev.2011.08.004

\section{Copyrights}

Copyright for this article is retained by the author(s), with first publication rights granted to the journal.

This is an open-access article distributed under the terms and conditions of the Creative Commons Attribution license (http://creativecommons.org/licenses/by/3.0/). 